\title{
The "Hoddle Muddle": using faith healers and other complementary therapists in sports medicine
}

When it was announced that Glenn Hoddle, the coach of the England football team, had recruited a faith healer to look after the players during the World Cup, a groan of agony went through the world of British sports medicine. Had the last bastion of common sense succumbed to mysticism and quackery?

Faith healing is only one of over 100 complementary therapies that are quickly growing in popularity in the United Kingdom and elsewhere. ${ }^{1}$ They have little in common beyond the fact that proponents are convinced of the superiority and universal applicability of each treatment. Complementary medicine (CM) encompasses primary care systems of medicine (including Traditional Chinese Medicine and homoeopathy, which have unique diagnostic criteria and diverse therapeutic options), discrete therapies (shark cartilage, bee pollen, coenzyme $\mathrm{Q}_{10}$, etc) and everything in between. ${ }^{2}$ A positive definition describing CM by what it is rather than by what it is not has recently been adopted by the Cochrane Field working in this area: "CM is diagnosis, treatment and/or prevention which complements mainstream medicine by contributing to a common whole, by satisfying a demand not met by orthodoxy or by diversifying the conceptual frameworks of medicine". ${ }^{3}$

Historically, CM has come and gone in major waves. For example, in the United States, Britain, and Germany of the mid to late nineteenth century, homoeopathy, hydropathy, and herbalism all thrived, only to dwindle into obscurity in the early twentieth century and experience a subsequent renaissance in our time. Sir William Osler's Principles and Practice of Medicine, first published in 1882, recommended acupuncture for sciatica and lumbago; the reference was expunged 30 years after Osler's death in $1919 .{ }^{4}$ Today no major textbook on pain fails to mention acupuncture.

Why do so many people today turn to CM? Reasons differ distinctly from one sample of users to another, but several recurring themes can be noted. Disillusionment with conventional medicine is one, and the hope to be cured without side effects is another. But the most important motivator is probably the urge to leave no option untried. ${ }^{5}$ "At least it won't do me any harm" is what people usually say or think.

The conditions most commonly treated by $\mathrm{CM}$ fall into two categories: common chronic benign conditions, such as musculoskeletal problems, anxiety, and stress as well as life threatening diseases such as cancer and AIDS. Athletes are prone to the former category of ailments and are therefore likely to try CM sooner or later. The only hard data on this come from Denmark where $47 \%$ of women and $35 \%$ of men attending a sports injury clinic had previously tried $\mathrm{CM}^{6}$

A survey from the United States shows that $72 \%$ of all patients seeing a provider of CM did not tell their physician about it. ${ }^{7}$ Although patients seem to fear censure, their doctors may be more open minded than they think. Some $44 \%$ of 594 US family doctors thought that faith healers and physicians could work together to cure some patients, and $23 \%$ believed that faith healers heal some patients whom physicians cannot help. ${ }^{8}$ A survey from the United Kingdom suggests that $68 \%$ of general practitioners had some contact with CM during the previous week, and most respondents felt that the major forms of CM should be refundable within the NHS. ${ }^{9}$ This, however, would incur considerable costs, according to a survey assessing the financial expectations of British providers of CM. ${ }^{10}$

Whether or not the integration of CM into the NHS would be worth while hinges on the question of whether, on balance, it does more good than harm. To answer it, one needs to assess each treatment modality on its own merit - for example, efficacy, safety, and cost. Generalisations are therefore problematic. Broadly speaking, however, the evidence for well informed decisions is often insufficient. ${ }^{11}$ This simply means that we need to do our homework properly and come up with the data. Unfortunately this will not be easy, quick or inexpensive.

To come back to Glenn Hoddle, some will think why not? Let him use whatever he feels could help without harm. Surely faith healing cannot do any harm! Or can it? Hopefully it will not harm our football team, but the sanctioning by VIPs of unproven and possibly ineffective treatments with intense press coverage has the power to do considerable damage indirectly. CHILD Inc is a US organisation that aims to protect children from inappropriate treatment by faith healers. This organisation apparently has 140 cases of children on file who died in this manner. ${ }^{12}$ This is where the "Hoddle Muddle" may well be much more than just another feast for the media or an embarrassment for down to earth sports enthusiasts. Double standards often have their price-and in medicine it is usually the patient who pays.

E ERNST

Department of Complementary Medicine, Postgraduate Medical School, University of Exeter, 25 Victoria Park Road, Exeter EX2 4NT, United Kingdom

1 Fisher P, Ward A. Complementary medicine in Europe. BMF 1994;309:107-11.

$2 \mathrm{Lin}$ JH. Evaluating the alternatives. $\mathcal{F A M A}$ 1998;279:706.

3 Ernst E, Resch KL, Mills S, et al. Complementary medicine: a definition. $\mathrm{Br}$ f Gen Pract 1995;45:506.

4 Lytle,CD. An overview of acupuncture. Rockville, MD: Center for Devices and Radiological Health, Food and Drug Administration, Public Health Service, 1993.

5 Ernst E, Willoughby M, Weihmayr TH. Nine possible reasons for choosing complementary medicine. Perfusion 1995;8:356-8.

6 Johannsen FE, Stallknecht BM, Langberg H. Alternative treatment of athletic injuries. Ugeskr Laeger 1995;157:2551-3.

7 Eisenberg DM, Kessler RC, Foster C, et al. Unconventional medicine in the United States. N Engl f Med 1993;328:246-52.

8 King DE, Sobal J, Haggerty J, et al. Experiences and attitudes about faith King DE, Sobal J, Haggerty J, et al. Experiences and attitudes

healing among family physicians. F Fam Pract 1992;35:158-62.
White AR, Resch K-L, Ernst E. Complementary medicine: use and attitudes White AR, Resch K-L, Ernst E. Complen
among GPs. Fam Pract 1997;14:302-6.

10 White AR, Resch K-L, Ernst E. A survey of complementary practitioners' fees, practice, and attitudes to working within the National Health Service. Complementary Therapy and Medicine 1997;5:210-14.

11 Ernst E. Complementary medicine: the facts. Physical Therapy Reviews 1997;2:49-57.

12 Barrett S. Some thoughts about faith healing. Website http:// www.quackwatch.com/01QuackeryRelatedTopics/faith.html. 